\title{
Food Insecurity and Pediatric Obesity: a Double Whammy in the Era of COVID-19
}

\author{
June M. Tester ${ }^{1,2}$ (D) Lisa G. Rosas ${ }^{3} \cdot$ Cindy W. Leung ${ }^{4}$ \\ Accepted: 7 October 2020 / Published online: 16 October 2020 \\ (C) Springer Science+Business Media, LLC, part of Springer Nature 2020
}

\begin{abstract}
Purpose of Review This review examines the current evidence about the ways in which food insecurity relates to obesity in children and adolescents, examining diet and diet-related behaviors, and taking into consideration the role of stress.

Recent Findings While living with food insecurity impacts stress and diet-related behaviors in children and adolescents, it is not clear whether food insecurity is associated with obesity above and beyond the influence of poverty. However, strategies to mitigate food insecurity and obesity are inherently connected, and recent examples from clinical practice (e.g., screening for food insecurity among patients) and advocacy (e.g., policy considerations regarding federal food programs such as the Supplemental Nutrition Assistance Program, or SNAP) are discussed.

Summary Food insecurity and obesity coexist in low-income children and adolescents in the USA. The COVID-19 pandemic exerts disproportionate burden on low-income children and families, magnifying their vulnerability to both food insecurity and pediatric obesity.
\end{abstract}

Keywords Food insecurity $\cdot$ Pediatric obesity $\cdot$ Screening $\cdot$ COVID

\section{Introduction}

Children who grow up in households with fewer financial resources have higher levels of obesity than children who grow up with more financial resources [1-4]. Low-income children are also more likely to be living in households experiencing food insecurity, [5] defined as "having inadequate access to sufficient, safe, and nutritious food to meet dietary needs and food preferences for an active and healthy

This article is part of the Topical Collection on Childhood Obesity

June M. Tester

june.tester@ucsf.edu

1 Division of Pediatric Endocrinology, UCSF Benioff Children's Hospital Oakland, 744 52nd Street, Oakland 94609, CA, USA

2 Department of Pediatrics, Division of Endocrinology, University of California, San Francisco, 550 16th Street, 4th Floor Box 0110, San Francisco, CA, USA

3 Epidemiology and Population Health, Stanford University, School of Medicine, Stanford, CA, USA

4 Department of Nutritional Sciences, University of Michigan School of Public Health, Ann Arbor, MI, USA lifestyle" [6]. Obesity and food insecurity coexist in many children and adolescents, and this seemingly paradoxical relationship has been increasingly described in the medical literature since a provocative medical case report published a quarter of a century ago [7]. Some of this literature has focused on determining whether food insecurity causes obesity among children and adolescents [8,9]. Regardless of whether the relationship is causal, food insecurity and obesity commonly co-occur, and each condition leads to significant adverse health and social consequences.

Addressing obesity and food insecurity as commonly cooccurring conditions merits focused attention as intervention strategies are intrinsically related. Addressing food insecurity requires providing resources for food or directly providing food, while addressing obesity requires changing the types and quantities of foods consumed. Thus, in order to optimize success, obesity prevention and treatment strategiesparticularly those that are aimed at supporting the health of children and adolescents from under-resourced backgrounds - must take food insecurity into consideration. Likewise, food assistance programs such as the federal Supplemental Nutrition Assistance Program (SNAP, or "food stamps")-which are not historically created to support healthy eating patterns, per se-have a role with influencing 
the dietary patterns among under-resourced populations that may contribute to obesity [10]. Strategies which address food insecurity while also focusing on healthy eating behaviors in children and adolescents will support health outcomes most optimally throughout the life course.

This review will examine the existing evidence about the ways in which food insecurity relates to obesity in children. Because the COVID-19 pandemic exerts disproportionate burden on low-income children, magnifying vulnerability, a special focus on relevant literature that has emerged in these past few months is also included.

\section{Food Insecurity and Dietary Intake in Children}

Poverty, with or without the layer of food insecurity, predisposes low-income individuals towards having a suboptimal diet. It is well-documented that low-income neighborhoods have limited food outlets stocked with fresh produce and whole grains ("food deserts") [11-13] and are often saturated with fast-food outlets and convenience stores carrying shelf-stable junk foods (also called "food swamps") [14]. Limited purchasing power also affects how one shops for household groceries. Nutrient-dense foods like fresh fruits and vegetables can have a high "per calorie" cost compared to calorie-dense junk foods $[15,16]$. In contrast, calorie-dense foods that are low in nutritional value are often cost-effective staples for keeping a lowincome household fed. For some households, having the ability to plan and prepare meals with low-cost, whole ingredients can be an important buffer against being otherwise vulnerable to food insecurity [17]. However, for many, the experience of food insecurity and its impact on diet is greater than the sum of limited funds and poor access to healthy food [18].

There is evidence in adults that food insecurity contributes to poor diet quality above and beyond the influence of poverty $[19,20]$. However, in contrast to what has been demonstrated in adults, it is not clear whether food insecurity adds additional independent influence on children's diet quality above and beyond the detrimental impact of poverty. A systematic review included 16 studies evaluating child data; food-insecure children may consume less fresh fruit than their peers, but it was not conclusive that diet quality was lower in the same way this was so strongly demonstrated for adults [20]. Some of these studies note a relationship between food insecurity and diet quality but only in adolescents [21]. In particular, foodinsecure adolescents report higher fast-food and dietary fat intake, compared to their peers [22]. Among low-income households with children, food-insecure kitchens are stocked with more obesity-promoting foods such as microwaveable and quick-cook frozen foods [23]. However, it is thought that the adults in food-insecure households protect their childrenparticularly younger ones - from compromised household dietary quality $[20,21,24]$.

\section{Food Insecurity, Chronic Stress, and Eating Behaviors}

Social stressors, including poverty, trauma, and physical abuse, are known to adversely affect children's health through the pathway of chronic stress. The resulting stress that children experience has been characterized as "toxic" by the National Scientific Council on the Developing Child, because of how it disrupts children's cognitive development and contributes to future risk of chronic disease $[25,26]$. A growing body of research has also highlighted the impact of food insecurity on children's experience of chronic stress; thus, elements of the toxic stress framework might help to conceptualize the relationship between food insecurity and diet-related outcomes such as obesity in low-income children.

Qualitative studies have demonstrated that children are not only aware of their household's food insecurity but are psychologically affected by it, often unbeknownst to the well-intentioned parents and caregivers attempting to shield their children from negative impact. In a study of children from 26 South Carolina families, children discussed feelings of worry, sadness, and anger related to food insecurity, which the authors characterized as "emotional awareness" [27]. Another study in the UK found that children's emotional response to food insecurity included sadness and irritation [28]. A more recent study revealed multiple dimensions of children's psychological distress related to food insecurity, including worry, anger and frustration, shame, family isolation, and sadness [29]. Children employed coping strategies such as distracting themselves from and increasing tolerance of their families' food situation. The chronic stress of food insecurity may explain why some food-insecure children have poorer quality diets than others. Chronic stress activates the hypothalamus pituitary adrenal (HPA) axis, which triggers a cascade of hormones leading to the eventual release of cortisol. Cortisol stimulates highly palatable food intake (e.g., processed foods high in fat and sugar), which can lead to excessive caloric intake [30, 31]. Given the abundance of access to unhealthy foods in low-income neighborhoods, some food-insecure children may eat not simply in response to their hunger cues but as a coping strategy to their ongoing experience of chronic stress.

Families living with food insecurity can also cycle between periods of food insufficiency and periods of relative stability or even abundance. Coping with food insecurity often includes a reliance on low-cost foods with binging when resources are available. Literature regarding adults has shown evidence of disordered or binge-type eating patterns among adults with food insecurity [32, 33, 34•], particularly when these adults had experienced food shortages as children [35]. 
Disordered eating behaviors have also been described in foodinsecure children as well. In one qualitative study of lowincome parent/caregivers of obese children, 7 focus groups were comprised of food-insecure (4 groups) and food-secure (3 groups) participants. While participants in all groups had anecdotes about overeating in their children, only respondents in the food-insecure groups described food-hiding, night-time eating episodes, and binge-type eating behaviors [36]. In an analysis of middle and high school adolescents who participated in two studies in Minnesota-EAT 2010 (Eating and Activity in Teens) and Project F-EAT (Families and Eating and Activity Among Teens) - the prevalence of unhealthy weight control behaviors was higher among adolescents who were food-insecure $(44.5 \%)$ compared to food-secure peers (37.8\%, $p<0.001)$, after adjusting for parental education, race/ethnicity, sex, and age [37]. In related analysis of adolescents in Project EAT over time, food insecurity in early/ middle adolescence (EAT-I) predicted increased risk of binge eating 5 years later during late adolescence/early adulthood (EAT-II) [38]. This suggests that food insecurity may be associated with disordered eating patterns in food-insecure children.

\section{Food Insecurity and Obesity in Children}

Since the 1990s, evidence in adults - particularly womensuggests that food insecurity may predispose towards having overweight or obesity [39-41]. For children, however, the evidence about the association between food insecurity and obesity has been mixed. A review published in 2011 identified 20 cross-sectional and five longitudinal studies evaluating the association between household food security and weight status in children and adolescents in the USA [8]. The majority $(n=9)$ showed no association [42-49], with some $(n=5)$ even suggesting that children living in food-insecure households were less likely to have obesity [50-54]. A small number of studies $(n=6)$ showed evidence of more weight gain and higher body mass index (BMI) in food-insecure children compared to food-secure peers [21, 22, 55-58]. Since this review, new analyses have been added to the mixed literature base. In a recent study, though there was a higher prevalence of overweight in food-insecure children, this was no longer significant after adjustment for other demographic factors [37]. Adding to the literature base suggesting a positive association, one study at a weight management clinic found that children from food-insecure households $(N=822)$ had higher BMI percentiles than those from food-secure households [59], and an analysis from the 2011 Kindergarten Cohort 2011 of the Early Childhood Longitudinal Study (ECLS) showed that first-grade food insecurity is an independent risk factor for longitudinal increases in BMI z-score in first through third grades [60].

\section{Identifying Food Insecurity in the Clinical Setting}

Pediatric healthcare visits are well suited to screening for social determinants of health given the frequency of touchpoints due to vaccinations and anticipatory guidance at each developmental level [61]. Screening tools for food security will vary based on the context. The gold-standard method (USDA Core Food Security Module) is a questionnaire with three stages and a total of up to 18 items [6]. This is the most comprehensive way to assess whether a household is fully food secure (living with a "high level of food security") or if there is "marginal level," "low," or "very low" food security, with these latter two levels comprising the more general category of "food insecurity." The length of this tool makes administration in a clinical setting difficult, and therefore shorter assessment tools have been developed [62, 63]. In 2010, two items taken from the full questionnaire were validated in a pediatric setting ( $N=30,098$ families) as a brief screening tool with a sensitivity of $97 \%$ and a specificity of $83 \%$ for identifying household food insecurity [64]. Dubbed the "Hunger Vital Sign," TM these two questions that query how often the household "worried whether food would run out before we got money to buy more" and "how often the food we bought just didn't last and we didn't have money to get more" have been validated across other high-risk clinical populations, as well [65]. Since then, this tool has been widely adopted into pediatric clinical practice given the importance of food insecurity for children's health outcomes [66].

Screening for food insecurity in clinical settings has led to a variety of strategies to address this important social determinant of health. A recent systematic review of interventions to address food insecurity in healthcare settings ( $n=23$ studies) documented four categories of approaches: (1) passive referrals to food resources, (2) active referral to food resources, (3) provision of food in the clinic, and (4) provision of food vouchers [67•]. Out of the 9 studies in pediatric populations, 3 provided passive referrals, 5 provided active referrals, and 1 provided passive referral and food. The studies of passive referrals documented that interventions to increase screening of food insecurity and referrals to resources were successful. However, the studies did not assess whether referrals turned into receipt of resources. The studies of active referrals documented that this approach was successful for supporting families to sign up for food assistance. One study that provided formula to mothers with food insecurity demonstrated that this was effective for improving healthcare utilization. This limited body of literature supports addressing food insecurity in healthcare settings and also identifies several important gaps in evidence to guide practice. 


\section{Considering Food Insecurity in the Context of Obesity Prevention and Management}

Because of the obesity epidemic, lifestyle counseling is an ever-present cornerstone of outpatient medical care. Pediatric providers, whether in primary care or in a specialized weight management setting, all give some kind of nutrition recommendations to their patients and families. Management of pediatric obesity largely focuses on education and improving self-efficacy to eat better [68]. However, explaining to patients and caregivers that they need to "eat less calorie-dense junk foods" and also somehow "eat more fruits and vegetables" can impart an insensitive tone without some understanding of the barriers that may be preventing this from happening. Normalizing the fact that it is "hard to eat healthy on a budget" can be helpful in brokering more honest conversations with parents and caregivers and identifying families at higher risk of household food insecurity. Insecure access to food may not only affect the quality and quantity of food that someone eats but may also impact the manner in which they eat it. Individual encounters with children and adolescents with obesity that are mindful of this dynamic in a non-judgmental way may uncover whether the patient is engaged in binge-type eating behaviors that are aggravated by insecure access to food.

In many instances, the collision between limited finances and a child's taste preferences complicates lifestyle counseling aimed at improving household food shopping. Studies about taste development suggest that children often refuse a novel food 8 to 15 times before accepting it [69]. Parents and caregivers with a limited food budget can be risk averse about spending money on food that might be wasted, preferring instead to purchase foods that they are certain their child will eat [70]. Some propose strategies to help parents set on a course of gradually exposing their children to foods that are on a "risk ladder" from foods that are inherently quickly accepted by children to ones that are less palatable (e.g., from sweeter vegetables progressing to bitter ones) [71]. Acknowledging that some parents do not purchase "healthy" foods out of concern for wasting limited resources rather than out of mere lack of interest or concern to improve diet is an example of patient-centered care that carries a higher likelihood of therapeutic success [72].

It is well-known that there is a wide variation in response to intervention among treatment-seeking adults $[73,74]$ and adolescents [75] with obesity. There has long been evidence in adults that low socioeconomic status predicts weight gain over time [76, 77]. Since 2013, there has been a US-based registry of 2-18-year-old children enrolled in pediatric weight management programs [78]. Early analyses have examined factors associated with greater or lesser improvement in weight status, suggesting that Hispanic race/ethnicity may be associated with greater improvement, though social determinants of health such as food insecurity have not yet been evaluated [79]. It may be that in youth, while food insecurity is not independently associated with development of obesity above and beyond poverty itself, it is a factor that makes weight improvement more challenging.

Knowledge about difficulty with access to food may inform the medical provider's communication with vulnerable families, particularly when it comes to recommendations they make to improve dietary habits. Pediatric weight management providers are already accustomed to assessing whether patients have disordered eating behaviors; binge eating and night-time eating behaviors are associated with increased weight gain and worsened metabolic health [80, 81]. The connections demonstrated thus far between food insecurity and disordered eating suggest inherent value in identification of food insecurity in patients seeking treatment for obesityscreening for food insecurity offers a more complete appraisal of the barriers faced by patients, regardless of whether or not food insecurity independently "causes" obesity in children.

\section{Considering Both Food Insecurity and Obesity in Policy and Advocacy}

In some aspects, anti-hunger and obesity advocacy can be at odds with one another. For example, the Supplemental Nutrition Assistance Program (SNAP) is the largest federal nutrition assistance program that provides resources to purchase food for low-income families. SNAP-Ed, a complementary program to SNAP, provides nutrition education to individuals eligible for SNAP, but education alone may not be enough to address the numerous barriers to healthy food access among SNAP recipients [82]. There are few guidelines about what foods can or cannot be purchased with SNAP benefits, resulting in controversies around modifications to the SNAP food package. Proposals such as providing financial incentives for healthy foods (e.g., fruits and vegetables) have garnered widespread support [83], but limiting the purchase of sugar-sweetened beverages with SNAP benefits has been rife with controversy due to concerns around implementation challenges, limited effectiveness in dietary improvement, and potential harms to the dignity of SNAP participants [84]. Despite this, a majority of SNAP participants have expressed broad support for proposals that promote healthier food options, as well as increasing the overall benefit allotment [85-87], which has long been argued to be inadequate to support a healthy diet $[88,89]$. In recent years, the conversation has shifted from improving nutrition policies within SNAP to protecting the program from fiscal cuts. During the Trump administration, proposals have attempted to (1) replace half of SNAP benefits with a box of shelf-stable staple food items (i.e., Harvest Box), (2) increase work requirements for "able-bodied" adults without children to remain in the 
program, and (3) eliminate categorical eligibility between SNAP and other safety net programs for low-income children and families. These proposals would have made otherwise eligible households lose their SNAP benefits or drastically change the foods available to them with SNAP benefits and resulted in expected increases in food insecurity and magnifying diet-related disparities in an already vulnerable population.

While administrative and nutrition policies for SNAP continue to be debated, there is evidence in the literature regarding the impact of nutrition-focused changes made to another federal nutrition assistance program - the Special Supplemental Assistance Program for Women Infants and Children (WIC). In 2009, after several decades of having had no changes, WIC revised their food package to include more fruits and vegetables, a greater focus on whole grains, and a dramatic reduction in the amount of fruit juice. Analysis of nationally representative data (NHANES) showed that as a result of the revised WIC package, diet quality scores in US preschool-aged children in WIC households improved, driven largely in part by increases in greens and beans and whole grains [90]. And an interrupted time series analysis of national WIC data regarding children 2-4 years showed a reversal in the trend towards rising obesity after the WIC package change [91]. Furthermore, changes to the WIC package appear to have led to improvements in access to local store availability of healthy foods, more broadly, benefitting non-WIC families as well [92].

Similar to WIC, another federal nutrition assistance program that had substantially changed their nutrition standards in recent years is the National School Lunch Program. Under the Healthy Hunger-Free Kids Act of 2010 (HHFKA), changes were made to increase the amount of fruits, vegetables, and whole grains; lower the fat content of milk; and cap the total amount of calories and sodium served. A 2017 review of multiple HHFKA evaluation studies found that multiple children's dietary behaviors improved as a result of healthier offerings during school lunch, including improved selection of healthy food, increased consumption of healthy foods, and minimal food waste [93]. Analysis of NHANES data before and after HHFKA was implemented found that students' diet quality scores increased overall and particularly on days when school foods were consumed as a result of the improved nutrition standards [94]. And, a recent study using national data from the National Survey of Children's Health found that HHFKA led to a significant decreased risk in obesity for children ages 10-17 living in poverty, due to their higher participation rates in school lunch programs. The authors estimated that approximately 500,000 fewer children living in poverty developed obesity as a result of HHFKA, leading to potential health benefits and economic savings long term [95].

In addition to changes in federal policy, there have also been important examples from the charitable food system (e.g., food banks) that show evidence of moving away from foods that may be high in calories but low in nutritional value. In a qualitative study (2015 to 2017) with leaders from 30 food banks across the USA, interviews showed that executive directors had multiple strategies to advance "nutrition-focused food banking," including building a healthier food inventory, enhancing healthy food storage capacity for partnering agencies, nutrition education outreach, and expanding community partnerships for healthy food distribution (e.g., healthcare locations) [96]. This marks a large shift in attitudes about "healthy versus unhealthy" foods in the charitable food system since the first food bank in the USA opened in 1967 [97].

\section{Implications of COVID-19 Pandemic}

The COVID-19 pandemic is exerting wide and far-reaching pressure on millions of people across the globe; one aspect of its impact is specifically with respect to food insecurity. In the early weeks of the pandemic, a national web-based survey of low-income US adults in March 2020 found that compared to peers also $<250 \%$ of the federal poverty level, those in foodinsecure households were less able to stock up on 2 weeks of additional food for their families due to insufficient resources [98]. In order to collect ongoing data during the pandemic, the COVID Impact Survey has sampled adults nationwide using an address-based random survey [99]. The survey consists of 25 questions, with two items querying about household food security using the 2-item "Hunger Vital Sign" [65]. During the week of April 20-26, 2020, 34.5\% of households with children surveyed were food insecure. Compared to national estimates for March 2020 using the same measure (11.6\%), the rate of food insecurity in late April had already tripled [100•].

Low-income children face particular vulnerabilities with respect to food insecurity that are magnified with the pandemic. For example, many low-income children depend on meals provided by schools and child care centers, and wide-spread school closures exacerbate food insecurity [101, 102]. For low-income families, this missed access to food resources is estimated to be a loss of at least $\$ 30$ of provided food per week for each child [103]. The true cost is likely even higher, given the need to spend more effort shopping for this food that is more costly to families at retail price than the bulk-purchasing rate which schools are charged [102]. Early strategies have leaned on applying approaches from the USDA summer feeding program; however, many schools are not accustomed to delivering food during the summer, and under usual circumstances, summer feeding programs only reach a seventh of the children who are served with the free and reduced-price meal program during the school year [104]. One early source of funding to mitigate the effects of the pandemic has been the Families First Coronavirus Response Act of 2020, which authorized the expansion of funds administered through SNAP 
to increase aid to families with children who would ordinarily receive free and reduced-price school meals [105], and the Coronavirus Aid, Relief and Economic Security (CARES) Act, which includes $\$ 15.5$ billion dollars to support increased demand for SNAP and $\$ 8.8$ billion dollars for child nutrition programs, specifically [106].

The novel circumstances that many families find themselves in as a result of the COVID-19 pandemic have important implications for children's obesity-related lifestyle behaviors. It has been demonstrated that summer vacation is a time of accelerated weight gain for many [107-109]. The "Structured Days Hypothesis" refers to how obesogenic behaviors (e.g., excessive snacking, increased screen time) are normally regulated when children have scheduled routines compared to lack of structured time during the summer [110]. School closures are likely to increase children's risk of weight gain for the same reasons that weight gain over the summer is well-documented [111]. An added, unique pressure from COVID-19 is the rational desire for families to stock up on foods to minimize shopping trips; the increased presence of foods in the home, particularly when they are shelfstable "comfort foods," is an additional temptation. Socioeconomic disparities are already well-documented to limit access to physical activity opportunities for lowincome children compared to their more affluent peers [112]. Because social distancing requirements narrow the range of safe places to be active - even public playgrounds and schoolyard grounds are off-limits - the pandemic only widens the gap even more.

Lastly, as it has been observed by one of the authors who is a pediatric obesity specialist, it is worth noting that for a few low-income children, home confinement has actually led to improvement in their health-related behaviors, rather than worsening. For some, because of the increased concerns and challenges with eating out of the home, there has been a sharp decline in eating out, with more meals that are prepared at home. It is known that longer work hours (particularly for mothers who are paid low wages) can translate to children needing to rely on more processed and convenience foods and have more unsupervised time that can lead to unhealthy behaviors [113]. Because of massive disruption to employment, many parents who would normally be out of the home working one or more jobs now find themselves at home and are consequently around and more able to supervise what their children and adolescents are eating.

\section{Conclusions}

Food insecurity and obesity coexist in low-income children and adolescents in the USA. Programs to address food insecurity in vulnerable patient populations can range in scope from small, local clinic-based interventions to federal programs such as the Supplemental Nutrition Assistance Program (SNAP) that reach millions of Americans. It is too early to say whether rates of pediatric obesity will increase due to COVID-19 after the plateau seen in recent years. However, it is clear that food insecurity has spiked during the pandemic, and given ongoing downstream effects from levels of unemployment not seen since the Great Depression, this vulnerability will continue for some time. In light of this, strategies to mitigate food insecurity and pediatric obesity will benefit from mutual consideration.

\section{Compliance with Ethical Standards}

Conflict of Interest The authors report no conflicts of interest with respect to the the preparation of this manuscript.

Human and Animal Rights and Informed Consent As this was a review paper, it was not human subjects research, and the question about human and animal rights and informed consent do not apply.

\section{References}

Papers of particular interest, published recently, have been highlighted as:

- Of importance

•. Of major importance

1. Ogden C, Lamb M, Carroll M, Flegal K. Obesity and socioeconomic status in children and adolescents: United States, 20052008. NCHS Data Brief. 2010;51:1-8.

2. Singh GK, Siahpush M, Kogan MD. Rising social inequalities in US childhood obesity, 2003-2007. Ann Epidemiol. 2010;20:40-52.

3. Wang Y, Zhang Q. Are American children and adolescents of low socioeconomic status at increased risk of obesity? Changes in the association between overweight and family income between 1971 and 2002. Am J Clin Nutr. 2006;84:707-16.

4. Jones-Smith JC, Dieckmann MG, Gottlieb L, Chow J, Fernald $\mathrm{LCH}$. Socioeconomic status and trajectory of overweight from birth to mid-childhood: the early childhood longitudinal studybirth cohort. PLoS One. 2014;9:e100181. https://doi.org/10. 1371/journal.pone.0100181.

5. Coleman-Jensen A, NordM, Singh A. Household food security in the united states in 2012, ERR-155, U.S. Department of Agriculture, Economic Research Service, Washington, DC. 2013.

6. Bickel G, Nord M, Price C, Hamilton W, Cook J. USDA, Guide to measuring household food security, revised 2000. U.S. Department of Agriculture, Food and Nutrition Service Alexandria VA. 2000.

7. Dietz WH. Does hunger cause obesity? Pediatrics. 1995;95:766-7.

8. Larson NI, Story MT. Food insecurity and weight status among U.S. children and families: a review of. Am J Prev Med. 2011;40: 166-73.

9. Eisenmann JC, Gundersen C, Lohman BJ, Garasky S, Stewart SD. Is food insecurity related to overweight and obesity in children and adolescents? A summary of studies, 1995-2009. Obes Rev. 2011;12:73-83.

10. Andreyeva T, Tripp AS, Schwartz MB. Dietary quality of Americans by supplemental nutrition assistance program 
participation status a systematic review. Am J Prev Med. 2015;49: 594-604.

11. Giang T, Karpyn A, Laurison HB, Hillier A, Perry RD. Closing the grocery gap in underserved communities: the creation of the Pennsylvania fresh food financing initiative. J Public Health Manag Pract. 2008;14:272-9.

12. Walker RE, Keane CR, Burke JG. Disparities and access to healthy food in the United States: a review of food deserts literature. Health Place. 2010;16:876-84.

13. Larson NI, Story MT, Nelson MC. Neighborhood environments. Disparities in access to healthy foods in the U.S. Am J Prev Med. 2009;36:74-81.e10.

14. Cooksey-Stowers K, Schwartz MB, Brownell KD. Food swamps predict obesity rates better than food deserts in the United States. Int J Environ Res Public Health. 2017;14:1-20.

15. Drewnowski A, Darmon N. Food choices and diet costs: an economic analysis. J Nutr. 2005;135:900-4.

16. Drewnowski A. The cost of US foods as related to their nutritive value. Am J Clin Nutr. 2010;92:1181-8.

17. Gundersen CG, Garasky SB. Financial management skills are associated with food insecurity in a sample of households with children in the United States. J Nutr. 2012;142:1865-70.

18. Laraia BA, Leak TM, Tester JM, Leung CW. Biobehavioral factors that shape nutrition in low-income populations: a narrative review. Am J Prev Med. 2017;52:S118-26. https://doi.org/10. 1016/j.amepre.2016.08.003.

19. Leung CW, Epel ES, Ritchie LD, Crawford PB, Laraia BA. Food insecurity is inversely associated with diet quality of lowerincome adults. J Acad Nutr Diet. 2014;114:1943-1953.e2.

20. Hanson KL, Connor LM. Food insecurity and dietary quality in US adults and children: a systematic review. Am J Clin Nutr. 2014;100:684-92.

21. Bhattacharya J, Currie J, Haider S. Poverty, food insecurity, and nutritional outcomes in children and adults. J Health Econ. 2004;23:839-62.

22. Widome R, Neumark-Sztainer D, Hannan PJ, Haines J, Story M. Eating when there is not enough to eat: eating behaviors and perceptions of food among food-insecure youths. Am J Public Health. 2009;99:822-8.

23. Nackers LM, Appelhans BM. Food insecurity is linked to a food environment promoting obesity in households with children. J Nutr Educ Behav. 2013;45:780-4.

24. Nord M, Andrews M, Carlson S. Household food security in the United States. 2013. United States Dep Agric Econ Res Rep No. 66.

25. National Scientific Council on the Developing Child. Excessive stress disrupts the architecture of the developing brain. 2005. Work. Pap. No.3.

26. Shonkoff JP, Garner AS, Siegel BS, et al. The lifelong effects of early childhood adversity and toxic stress. Pediatrics. 2012;129: e232-46. https://doi.org/10.1542/peds.2011-2663.

27. Fram MS, Frongillo EA Jr, Jones SJ, Williams RC, Burke MP, De Loach KP, et al. Children are aware of food insecurity and take responsibility for managing food resources. J Nutr. 2011;141: 1114-9.

28. Harvey K. "When I go to bed hungry and sleep, I'm not hungry": children and parents' experiences of food insecurity. Appetite. 2016;99:235-44.

29. Leung CW, Stewart AL, Portela-Parra ET, Adler NE, Laraia BA, Epel ES. Understanding the psychological distress of food insecurity: a qualitative study of children's experiences and related coping strategies. J Acad Nutr Diet. 2020;120:395-403.

30. Adam TC, Epel ES. Stress, eating and the reward system. Physiol Behav. 2007;91:449-58.

31. Dallman MF. Stress-induced obesity and the emotional nervous system. Trends Endocrinol Metab. 2010;21:159-65.
32. Bruening M, MacLehose R, Loth K, Story M, Neumark-Sztainer D. Feeding a family in a recession: food insecurity among Minnesota parents. Am J Public Health. 2012;102:520-6.

33. Kendall A, Olson CM, Frongillo EA Jr. Relationship of hunger and food insecurity to food availability and consumption. J Am Diet Assoc. 1996;96:1019-24.

34. Seligman HK, Berkowitz SA. Aligning programs and policies to support food security and public health goals in the United States. Annu Rev Public Health. 2019;40:319-37 This paper provides relevant description of opportunities to align programs and policies that simultaneously support food security as well as improved diet quality.

35. Olson CM, Bove CF, Miller EO. Growing up poor: long-term implications for eating patterns and body weight. Appetite. 2007;49:198-207.

36. Tester JM, Lang TC, Laraia BA. Disordered eating behaviours and food insecurity: a qualitative study about children with obesity in low-income households. Obes Res Clin Pract. 2015;10:544-52. https://doi.org/10.1016/j.orcp.2015.11.007.

37. Hooper L, Telke S, Larson N, Mason SM, Neumark-Sztainer D. Household food insecurity: associations with disordered eating behaviours and overweight in a population-based sample of adolescents. Public Health Nutr. 2020:1-10. https://doi.org/10.1017/ S1368980020000464.

38. West CE, Goldschmidt AB, Mason SM, Neumark-Sztainer D. Differences in risk factors for binge eating by socioeconomic status in a community-based sample of adolescents: findings from project EAT. Int J Eat Disord. 2019;52:659-68.

39. Crawford PB, Webb KL. Unraveling the paradox of concurrent food insecurity and obesity. Am J Prev Med. 2011;40:274-5.

40. Townsend MS, Peerson J, Love B, Achterberg C, Murphy SP. Food insecurity is positively related to overweight in women. $\mathrm{J}$ Nutr. 2001;131:1738-45.

41. Adams EJ, Grummer-Strawn L, Chavez G. Food insecurity is associated with increased risk of obesity in California women. J Nutr. 2003;133:1070-4.

42. Gundersen C, Lohman BJ, Garasky S, Stewart S, Eisenmann J. Food security, maternal stressors, and overweight among lowincome US children: results from the National Health and Nutrition Examination Survey (1999-2002). Pediatrics. 2008; 122:e529-40.

43. Gundersen C, Garasky S, Lohman BJ. Food insecurity is not associated with childhood obesity as assessed using multiple measures of obesity. J Nutr. 2009;139:1173-8.

44. Bronte-Tinkew J, Zaslow M, Capps R, Horowitz A, McNamara M. Food insecurity works through depression, parenting, and infant feeding to influence overweight and health in toddlers. J Nutr. 2007;137:2160-5.

45. Winicki J, Jemison K. Food insecurity and hunger in the kindergarten classroom: its effect on learning and growth. Contemp Econ Policy. 2003;21:145-57.

46. Bhargava A, Jolliffe D, Howard LL. Socio-economic, behavioural and environmental factors predicted body weights and household food insecurity scores in the early childhood longitudinal studykindergarten. Br J Nutr. 2008;100:438-44.

47. Feinberg E, Kavanagh PL, Young RL, Prudent N. Food insecurity and compensatory feeding practices among urban black families. Pediatrics. 2008;122:1-13.

48. Kaiser LL, Melgar-Quiñonez HR, Lamp CL, Johns MC, Sutherlin JM, Harwood JO. Food security and nutritional outcomes of preschool-age Mexican-American children. J Am Diet Assoc. 2002;102:924-9.

49. Martin KS, Ferris AM. Food insecurity and gender are risk factors for obesity. J Nutr Educ Behav. 2007;39:31-6. 
50. Rose JD, Bodor. Household food insecurity and overweight status in Young school children: results from the early childhood longitudinal study. Pediatrics. 2006;117:464-73.

51. Jones SJ, Jahns L, Laraia BA, Haughton B. Lower risk of overweight in school-aged food insecure girls who participate in food assistance: results from the panel study of income dynamics child development supplement. Arch Pediatr Adolesc Med. 2003;157: $780-4$.

52. Buscemi J, Beech B, Relyea G. Predictors of obesity in Latino children: acculturation as a moderator of the relationship between food insecurity and body mass index percentile. J Immigr Minor Health. 2011;13:149-54.

53. Matheson DM, Varady J, Varady A, Killen JD. Household food security and nutritional status of Hispanic children in the fifth grade. Am J Clin Nutr. 2002;76:210-7.

54. Borre K, Ertle L, Graff M. Working to eat: vulnerability, food insecurity, and obesity among migrant and seasonal farmworker families. Am J Ind Med. 2010;53:443-62.

55. Smith C, Richards R. Dietary intake, overweight status, and perceptions of food insecurity among homeless Minnesotan youth. Am J Hum Biol. 2008;20:550-63.

56. Alaimo K, Olson CM, Frongillo EA. Low family income and food insufficiency in relation to overweight in US children: is there a paradox? Arch Pediatr Adolesc Med. 2001;155:1161-7.

57. Jyoti DF, Frongillo EA, Jones SJ. Food insecurity affects school children's academic performance, weight gain, and social skills. J Nutr. 2005;135:2831-9.

58. Metallinos-Katsaras E, Must A, Gorman K. A longitudinal study of food insecurity on obesity in preschool children. J Acad Nutr Diet. 2012;112:1949-58.

59. Oberle MM, Romero Willson S, Gross AC, Kelly AS, Fox CK. Relationships among child eating behaviors and household food insecurity in youth with obesity. Child Obes. 2019;15:298-305.

60. Lee AM, Scharf RJ, DeBoer MD. Association between kindergarten and first-grade food insecurity and weight status in U.S. children. Nutrition. 2018;51-52:1-5.

61. Beck AF, Tschudy MM, Coker TR, Mistry KB, Cox JE, Gitterman BA, et al. Determinants of health and pediatric primary care practices. Pediatrics. 2016;137:e20153673. https://doi.org/ 10.1542/peds.2015-3673.

62. Blumberg SJ, Bialostosky K, Hamilton WL, Briefel RR. The effectiveness of a short form of the household food security scale. Am J Public Health. 1999;89:1231-4.

63. Kleinman R, Murphy J, Wieneke K, Desmond M, Schiff A, Gapinski J. Use of a single-question screening tool to detect hunger in families attending a neighborhood health center. Ambul Pediatr. 2007;7:278-84.

64. Hager ER, Quigg AM, Black MM, Coleman SM, Heeren T, RoseJacobs R, et al. Development and validity of a 2-item screen to identify families at risk for food insecurity. Pediatrics. 2010;126: e26-32. https://doi.org/10.1542/peds.2009-3146.

65. Gundersen C, Engelhard EE, Crumbaugh AS, Seligman HK. Brief assessment of food insecurity accurately identifies high-risk US adults. Public Health Nutr. 2017;20:1367-71.

66. Barnidge E, LaBarge G, Krupsky K, Arthur J. Screening for food insecurity in pediatric clinical settings: opportunities and barriers. J Community Health. 2017;42:51-7.

67. De Marchis EH, Torres JM, Benesch T, Fichtenberg C, Allen IE, Whitaker EM, et al. Interventions addressing food insecurity in health care settings: a systematic review. Ann Fam Med. 2019;17: 436-47 This systematic review examines health care-based food insecurity interventions.

68. Barlow SE. Expert committee recommendations regarding the prevention, assessment, and treatment of child and adolescent overweight and obesity: summary report. Pediatrics. 2007;120: S164-92. https://doi.org/10.1542/peds.2007-2329C.
69. Sullivan S, Birch L. Pass the sugar, pass the salt: experience dictates preference. Dev Psychol. 1990;26:546-51.

70. Daniel C. Economic constraints on taste formation and the true cost of healthy eating. Soc Sci Med. 2016;148:34-41.

71. Connell PM, Finkelstein SR, Scott ML, Vallen B. Helping lower income parents reduce the risk of food waste resulting from children's aversion to healthier food options: comment on Daniel (2016). Soc Sci Med. 2016;150:286-9.

72. Levinson W, Lesser CS, Epstein RM. Developing physician communication skills for patient-centered care. Health Aff. 2010;29: 1310-8.

73. MacLean PS, Rothman AJ, Nicastro HL, Czajkowski SM, AgursCollins T, Rice EL, et al. The Accumulating Data to Optimally Predict Obesity Treatment (ADOPT) Core Measures Project: rationale and approach. Obesity. 2018;26:S6-S15.

74. MacLean PS, Wing RR, Davidson T, et al. NIH working group report: innovative research to improve maintenance of weight loss. Obesity. 2015;23:7-15.

75. Ryder JR, Kaizer AM, Jenkins TM, Kelly AS, Inge TH, Shaibi GQ. Heterogeneity in response to treatment of adolescents with severe obesity: the need for precision obesity medicine. Obesity. 2019;27:288-94.

76. Ball K, Crawford D. Socioeconomic status and weight change in adults: a review. Soc Sci Med. 2005;60:1987-2010.

77. Lantz PM, Lynch JW, House JS, Lepkowski JM, Mero RP, Musick MA, et al. Socioeconomic disparities in health change in a longitudinal study of US adults: the role of health-risk behaviors. Soc Sci Med. 2001;53:29-40.

78. Kirk S, Armstrong S, King E, Trapp C, Grow M, Tucker J, et al. Establishment of the pediatric obesity weight evaluation registry: a National Research Collaborative for identifying the optimal assessment and treatment of pediatric obesity. Child Obes. 2017;13:9-17.

79. Kumar S, King EC, Christison AL, et al. Health outcomes of youth in clinical pediatric weight management programs in POWER. J Pediatr. 2019;208:57-65.e4.

80. Tanofsky-Kraff M, Shomaker LB, Stern EA, Miller R, Sebring N, DellaValle D, et al. Children's binge eating and development of metabolic syndrome. Int J Obes. 2012;36:956-62.

81. Hudson JI, Lalonde JK, Coit CE, Tsuang MT, McElroy SL, Crow SJ, et al. Longitudinal study of the diagnosis of components of the metabolic syndrome in individuals with binge-eating disorder. Am J Clin Nutr. 2010;91:1568-73.

82. Gosliner W, Shah H. Participant voices: examining issue, program and policy priorities of SNAP-Ed eligible adults in California. Renew Agric Food Syst. 2019;35:407-15. https://doi.org/10. 1017/S1742170519000243.

83. Leung CW, Hoffnagle EE, Lindsay AC, Lofink HE, Hoffman VA, Turrell S, et al. A qualitative study of diverse experts' views about barriers and strategies to improve the diets and health of supplemental nutrition assistance program (SNAP) beneficiaries. J Acad Nutr Diet. 2013;113:70-6.

84. Schwartz MB. Moving beyond the debate over restricting sugary drinks in the supplemental nutrition assistance program. Am J Prev Med. 2017;52:S199-205.

85. Leung CW, Ryan-Ibarra S, Linares A, Induni M, Sugerman S, Long MW, et al. Support for policies to improve the nutritional impact of the supplemental nutrition assistance program in California. Am J Public Health. 2015;105:1576-80.

86. Leung CW, Musicus AA, Willett WC, Rimm EB. Improving the nutritional impact of the supplemental nutrition assistance program: perspectives from the participants. Am J Prev Med. 2017;52:S193-8.

87. Leung CW, Wolfson JA. Perspectives from supplemental nutrition assistance program participants on improving SNAP policy. Health Equity. 2019;3:81-5. 
88. Davis GC, You W. Not enough money or not enough time to satisfy the thrifty food plan? A cost difference approach for estimating a money-time threshold. Food Policy. 2011;36:101-7.

89. Davis GC, You W. The thrifty food plan is not thrifty when labor cost is considered. J Nutr. 2010;140:854-7.

90. Tester JM, Leung CW, Crawford PB. Revised WIC food package and children's diet quality. Pediatrics. 2016;137:e20153557. https://doi.org/10.1542/peds.2015-3557.

91. Daepp MIG, Gortmaker SL, Claire Wang Y, Long MW, Kenney EL. WIC food package changes: trends in childhood obesity prevalence. Pediatrics. 2019;143:e20182841. https://doi.org/10.1542/ peds.2018-2841.

92. Andreyeva T, Luedicke J, Middleton AE, Long MW, Schwartz MB. Positive influence of the revised special supplemental nutrition program for women, infants, and children food packages on access to healthy foods. J Acad Nutr Diet. 2012;112:850-8.

93. Mansfield JL, Savaiano DA. Effect of school wellness policies and the healthy, hunger-free kids act on food-consumption behaviors of students, 2006-2016: a systematic review. Nutr Rev. 2017;75:533-52.

94. Berger A, Widome R, Erickson DJ, Laska MN, Harnack LJ. Changes in association between school foods and child and adolescent dietary quality during implementation of the Healthy, Hunger-Free Kids Act of 2010. Ann Epidemiol. 2020;47:30-6.

95. Kenney EL, Barrett JL, Bleich SN, Ward ZJ, Cradock AL, Gortmaker SL. Impact of the healthy, hunger-free kids act on obesity trends. Health Aff (Millwood). 2020;39:1122-9.

96. Wetherill MS, White KC, Seligman HK. Nutrition-focused food banking in the United States: a qualitative study of healthy food distribution initiatives. J Acad Nutr Diet. 2019;119:1653-65.

97. St. Mary's Food Bank. Alliance. Our history. https://www. firstfoodbank.org/about/. Accessed July 7, 2020.

98. Wolfson JA, Leung CW. Food insecurity and COVID-19: disparities in early effects for us adults. Nutrients. 2020;12:1-12.

99. COVID Impact Survey. https://www.covid-impact.org/.

100. Schanzenbach D, Pitts A. Estimates of food insecurity during the covid-19 crisis: results from the COVID Impact Survey, Week 1 ( April 20-26, 2020 ). 2020; 1:1-12. This analysis provided early evidence of markedly increased food insecurity among families with children in the early months of the COVID pandemic in the US.

101. Van Lancker W, Parolin Z. COVID-19, school closures, and child poverty: a social crisis in the making. Lancet Public Health. 2020;5:e243-4.
102. Dunn CG, Kenney E, Fleischhacker SE, Bleich SN. Feeding lowincome children during the Covid-19 pandemic. N Engl J Med. 2020;382:e401-3.

103. The United States Department of Agriculture Food and Nutrition Service. National School Lunch, Special Milk, and School Breakfast Programs, national average payments/maximum reimbursement rates. 84 FR 38590. https://www.federalregister.gov. August 7, 2019.

104. United States Department of Agriculture (USDA), Economic Research Service. Definitions of Food Security. Available at: http://www.ers.usda.gov/topics/food-nutrition-assistance/foodsecurity-in-the-us/definitions-of-food-security.aspx. Last accessed Decemb.

105. Families First Coronavirus Response Act H.R. 6201- 116th Congress (2019-2020).

106. H.R. 748, CARES Act, Public Law 116-136.

107. Baranowski T, O'Connor T, Johnston C, Hughes S, Moreno J, Chen TA, et al. School year versus summer differences in child weight gain: a narrative review. Child Obes. 2014;10:18-24.

108. Franckle R, Adler R, Davison K. Accelerated weight gain among children during summer versus school year and related racial/ ethnic disparities: a systematic review. Prev Chronic Dis. 2014;11:1-10.

109. Von Hippel PT, Powell B, Downey DB, Rowland NJ. The effect of school on overweight in childhood: gain in body mass index during the school year and during summer vacation. Am J Public Health. 2007;97:696-702.

110. Brazendale K, Beets MW, Weaver RG, Pate RR, TurnerMcGrievy GM, Kaczynski AT, et al. Understanding differences between summer vs. school obesogenic behaviors of children: the structured days hypothesis. Int J Behav Nutr Phys Act. 2017;14: $1-14$.

111. Rundle AG, Park Y, Herbstman JB, Kinsey EW, Wang YC. COVID-19-related school closings and risk of weight gain among children. Obesity. 2020;28:1008-9.

112. Tanumihardjo SA, Anderson C, Kaufer-Horwitz M, Bode L, Emenaker NJ, Haqq AM, et al. Poverty, obesity, and malnutrition: an international perspective recognizing the paradox. J Am Diet Assoc. 2007;107:1966-72.

113. Datar A, Nicosia N, Shier V. Maternal work and children's diet, activity, and obesity. Soc Sci Med. 2014;107:196-204.

Publisher's Note Springer Nature remains neutral with regard to jurisdictional claims in published maps and institutional affiliations. 